University of Louisville

ThinkIR: The University of Louisville's Institutional Repository

Electronic Theses and Dissertations

1937

\title{
A biochemical study of colloidal sulfur.
}

Gertrude L. Hendershot

University of Louisville

Follow this and additional works at: https://ir.library.louisville.edu/etd

Part of the Chemistry Commons

\section{Recommended Citation}

Hendershot, Gertrude L., "A biochemical study of colloidal sulfur." (1937). Electronic Theses and Dissertations. Paper 1796.

https://doi.org/10.18297/etd/1796

This Master's Thesis is brought to you for free and open access by ThinkIR: The University of Louisville's Institutional Repository. It has been accepted for inclusion in Electronic Theses and Dissertations by an authorized administrator of ThinkIR: The University of Louisville's Institutional Repository. This title appears here courtesy of the author, who has retained all other copyrights. For more information, please contact thinkir@louisville.edu. 
UNIVERSITY OF LOUISVILIE

A BIOCHERICAL STUDY OF COLLOIDAL SULFUR

A Dissertation

Submitted to the Faculty

Of the Graduate School of the University of Louisville

In Partiel Fulfillment of the

Requirements for the Degree

Of Master of Science

Department of Chemistry

$\mathrm{By}$

GERTRUDE L. HENDEPSHOT 
Name: Gertrude L. Hendershot

Title: A Biochemical Study of Colloidal Sulfur

Direotor: Dr. A. W. Homberger

Approved by:

Reading Committer

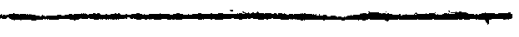

Representative of the

English Department

June 1, 1937 
ACKNOWLEDGEIENT

The author wishes to express her sincere appreciation to Dr.A. W. Homberger, who directed this research, for his many helpful suggestions and encouragement. The writer also wishes to thank the students in the Freshman Class of the Hedical. School for their kind assistance on the urine analyses. 
TABLE OF CONTENTS

Page No.

I. Introduction

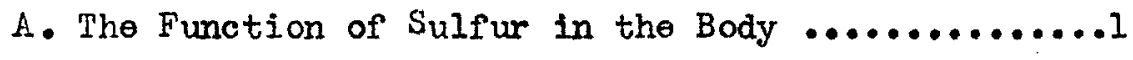

B. History of the Use of Sulfur ................4

II. Colloidal Sulfur

A. Properties ..............................11

B. Methods of Preparation of Colloidal Sulfur ......15

C. Difficulties in Holding Colloidal Sulfur in

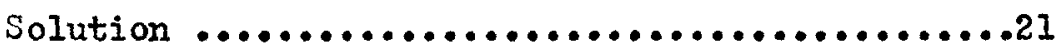

III. Objectives of This Research .................22

IV. pH Determinations of the Alkaline Polysulfide

Solution

A. Method .................................24

B. Results ..............................25

C. Discussion $\ldots \ldots \ldots \ldots \ldots \ldots \ldots \ldots \ldots \ldots \ldots \ldots \ldots$

V. The Quantitative Analysis of Colloidal Sulfur

A. Prevailing Methods ......................26

B. Method of Determination ...................29

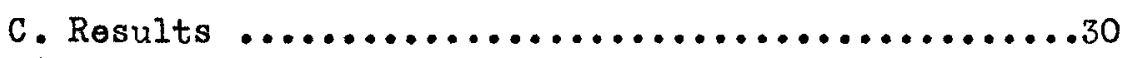

D. Discussion $\ldots \ldots \ldots \ldots \ldots \ldots \ldots \ldots \ldots \ldots \ldots \ldots \ldots$ 
VI. Diffusion of the Alkaline Polysulfide Solution

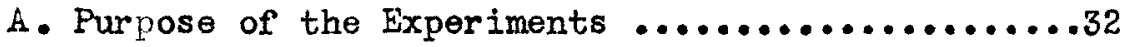

B. Procedure $\ldots \ldots \ldots \ldots \ldots \ldots \ldots \ldots \ldots \ldots \ldots \ldots \ldots \ldots \ldots \ldots 32$

C. Results of Diffusion Experiments .................

D. Discussion $\ldots \ldots \ldots \ldots \ldots \ldots \ldots \ldots \ldots \ldots \ldots \ldots \ldots \ldots \ldots$

VII. Total Sulfur in the Urine of Normal Individuals and in the Urine of Arthritic Patients

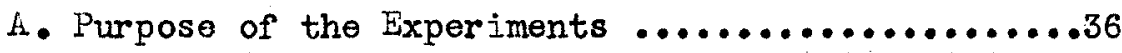

B. Mothod $\ldots \ldots \ldots \ldots \ldots \ldots \ldots \ldots \ldots \ldots \ldots \ldots \ldots \ldots \ldots \ldots . \ldots \ldots$

C. Results of the Determinations on Normal Urines ..39

D. Discussion $\ldots \ldots \ldots \ldots \ldots \ldots \ldots \ldots \ldots \ldots \ldots \ldots \ldots \ldots \ldots 40$

E. Results of the Determinations on the Urines of Arthritic Patients ......................41

F. Discussion $\ldots \ldots \ldots \ldots \ldots \ldots \ldots \ldots \ldots \ldots \ldots \ldots \ldots \ldots . \ldots 42$

G. Comparison and Causes of Possible Discrepancies .43 VIII, Summary of Conclusions ..................44 Bibliography $\ldots \ldots \ldots \ldots \ldots \ldots \ldots \ldots \ldots \ldots \ldots \ldots \ldots \ldots \ldots . \ldots 4$ 
I. INTRODUCTION 
A. The Function of Sulfur in the Body

In the human body sulfur has one of the most important roles. Sulfur compounds that are found in the body may be divided into three main groups. In the first group is the inorganic sulfur which includes salts of sulfuric acid and the alkaline metals, especially sodium and potassium, found thus in the blood, all body fluids, and practically all tissues. In the second group is the non-protein sulfur, the group including conjugated or ethereal sulfates, sulfo-lipoids, and ergothionine, a sulfur compound found in the red blood cells. The third group containing the protein sulfur is the largest group. It includes cystine, cysteine and glutathione (amino acids essential to the maintainance of life and the oxidation and reduction processes of tissues and the blood), prosthetic groups of glycoproteins (mucoitin, chondroitin-sulfuric acid, and melanins), thio-polypeptides, and loosely bound sulfur. In the urine the sulfur is found as mineral sulfates, ethereal sulfates, and neutral sulfur. Sulfur excretion depends on protein catabolism. The N:S ratio varies normally between 13 and 16 . Taurine, one of the bile acids, contains sulfur. Sulfur is found in loose combination in insulin. It is found in the cartilage as chondroitin-sulfuric acid and as neutral sulfur, which help maintain the pH of the cartilage at 7.8 and give the joint its suppleness and resistance. Sulfur is an important detoxifying agent. Indole and skatole, intestinal poisons, and also phenol and paracresol are eliminated in the urine combined with the sulfate radical. 
Sullivan and Hess state that in "the sulfur metabolism the normal body has a ready, though limited, means of defense. Detoxication seems a prominent role of the system cystine, cysteine, and glutathione." (1)

Cystine is an important constituent of fingernails. Woldenberg (2) believes that cystine is formed from cysteine, and that by a reduction process normal cornification is favored. He explains that cell growth and cell division must cease before cornification can take place. When oxygen is removed cell life ceases. Since the cysteine-cystine reaction may be reversed through a process of oxidation, according to Woldenberg, the presence of hydrogen sulfide might check this process by absorbing all the available oxygen to form sulfurous acid, thus enhancing complete keratinization.

Parnenter states: "According to Zunz sulfur applied to the skin is imnediately changed into a form which permits it to reach the cystine containing epidermal cells. It is changed by cystine into hydrogen sulfide and in the presence of hydrogen sulfide the sulfur soluble polysulfides are formed which liberate sulfur into the deep layers of the epidermis. This sulfur reacts with the thionic groups contained normally in the deep epidermis forming di-sulfides and hydrogen sulfide. These disulfides eventually become pentathionic acid which along with sulfur itself exerts a

(1) Sullivan and Hess: "Cystine Content of Fingernails in Arthritis", J. Bone and Joint Surg. Jan. 1934, p.187

(2) Woldenberg, S.C."Sulfur (Colloidal) Therapy in the Treatment of Arthritis", Med. Bulletin, U. S. Vet. Admin. 12, 1935-36, $\mathrm{p} \cdot 10-26$. 
detoxifying action." (1)

In normel sulfur metabolism Woldenberg (2) distinguishes three pheses: first, the dissociation of sulfur from protein as previously oxidized or neutral sulfur (twenty per cent of this noutral sulfur is eliminated unchanged in the urine); second, further oxidation of the greater part of the neutral sulfur; and third, the complete oxidation to sulfuric acid which enters into combination with certain alkaline bases and is eliminated through the urine as mineral sulfetes.

Parmenter (3) believes that polysulfides formed from hydrogen sulfide are reabsorbed and enter the blood or the cells and give up the excess sulfur which can then be oxidized or reduced. Miller, Osterberg, and others (4) think that the last product of this oxidation is pentathionic acid.

(1) Parmenter, D. C. "Sulfur Therapy in Arthritis" Hy. Hed. J. Jan. $1937,0.14$

(2) Woldenberg, S. C. op.cit. p.10-26

(3) Parmenter, D. C. op.cit. p.15

(4) Ibid. 
B. History of the Use of Sulfur

The role of sulfur is so important that it has merited much study especially in the past few years. Sulfur has long been a remedy for many diseases. The ancients, although they knew nothing of the action of sulfur in the body, recognized its therapeutic values. The early Greeks (I) praised the benefits of sulfur containing waters for both bathing and drinking. liany people today still think highly of the values of sulfur waters. The Greeks called it "theriou" meaning "divine". It is mentioned in the Bible as brimstone. Pliny (2) long ago suggested its use in an ojntment, and Roman writers of his time mention its use in the treatment of skin diseases. Paracelsus (3) during the Renaissance praises its use in the treatment of fevers. Rheumatism and lumbago sufferers have been treated with sulfur since the middle ages, and up to this day sulfur has been a popular remedy for those diseases. The method used to introduce sulfur into the body was the oral administration of flowers of sulfur. "Chelsea Pensioner" (4) was the name given to one of the most commonly used preparations.

In the first part of this century physicians began to use sulfur in the colloidal state. This form of sulfur as a therapeutic agent made its first appearance in Europe. In 1907 Bory (5)

(1) Parmenter, D. C. op.cit. p.10-26

(2) Comrie, J. D. "The Treatment of "Trench Pheumatism" and Allied Conditions with Colloidal Sulfur," Lancet, I, 1917, .991

(3) Ibid.

(4) Ibid:

(5) Soshen, D. and Spanbock, J. "Intravenous Injections of Colloidal Sulfur in the Treatment of Pheumatoid and Ostecarthritis," M. Rec. v.142, pp. 332-34. 
gave intravenous and intramuscular injections of sulfur in glycerine. In 1912 Cawadias (1) used colloidal sulfur. Comrie (2) in 1917 used a colloidal sulfur solution stabilized by egs white in the treatment of "trench rheumatism" and allied conditions. Cormie found that intramuscular injections of collojdal sulfur helped relieve the painful conditions in the affleted muscles and joints. Meyer-Bisch (3) in 1921 used a suspension of sulfur in olive oil. The production of fever has lons been used in the treatment of certain types of insanity. In 1931 Nackay (4) used a 2 per cent solution of sulfur in oil injection to produce fever in cases of dementia paralytica. He obtained fairly satisfactory results. Waller and Allen (5) in 1931 and 1932 used a 2 per cent solution or sulfur in olive oil to produce fever as a treatment of peripheral vascular diseases. Sulfosin, a preparation of sulfur in olive oil, was used in 1929 by Knud Schroeder (6) in the treatment of general paralysis and other diseases having non-syphilitic lesions of the central nerrous system. The benefit seemed to be caused by the fever resulting from the reaction produced by injecting the sulfur. This treatment was recommended to replace treatment of insanity by infection. Power (7) used a one per cent solution of sulfur in olive oil in the treatment of paralytic insanity and

(1) Soshen and Spanbock, op. cit. po.332-34

(2) Comrie, J. D. op. cit. p.991

(3) Soshen and Spanbock, op. cit. pp.332-34

(4) Nackay, R. P. "Sulfur in the Production of Fever,"Arch. Neur. and Psychiatry, v. 26, 1931, p.102

(5) Waller and Allen, "The Use of Sulfur for the Production of Fever in Peripheral Vascular Diseases" hnn. Int. Ned. v.5, 1932-32,p.478

(6) Schroeder, K. "Sulfosin Treatment of General Paralysis and Other Disorders", Lancet II, 1029, p. 1081-84

(7) Powrer, T. D. "Leucopoietic Value of Sulfur," Lancet i, 1932, p.338 
and dementia praecox with good results. McCartan and Beef (1) obtained some benefit in the treatment of dementia praecox with "Sulfosin". Farris (2) found that the fever produced from sulfur in oil and colloidal sulfur gave beneficjal results in the treatment of general paralysis.

The use of sulfur in treating arthritis began mainly after Comrie's success in the treatment of trench rheumatism. We find that Malnar (3) in 1931, Hyne (4) in 1923, Dengler (5) in 1924, and Rodel (6) in 1929 used sulfur in the treatment of arthritis. In the United States Senturia, Wheeldon, Argy, and Woldenberg have recorded interesting results in the use of colloidal sulfur in the treatment of this great economically wasteful disease.

Senturia (7) in his experiment treated all kinds of arthritisatrophic, hypertrophic and mixed types- with a preparation called "Sulfur Diasporal". Sulfur Diasporal is supplied in two forms: a 200 . ampule supposedly conteining $5 \mathrm{mg}$. of colloidal sulfur in a protein-free aqueous medium for intravenous injection; and a 2 cc. ampule conteining $20 \mathrm{mg}$. of colloidal sulfur in olive oil for intramuscular injections. Other kinds of treatment were omitted. Between the third and tenth injections the patients began to show improvement. Senturia believes that treatment by colloidal sulfur

(1) MeCartan, $\|_{0}$ and Beef, D." Preatment of Dementia Praecox with Sulfosin," Lancet, i, 1932 , D. 340

(2) Harris, N. G."Treatment of General Paralys is of the Insane by Injection of Sulfur Lancet, 1930, p.1068-69

(3) Soshen, D. and Spanbock, J. op. cit. pp.332-34

(4) Ibid.

(5) Ibid.

(6) Ibid.

(7) Senturia, B. D."Results of Treatment of Chronic Arthritis and Rheumatoid Conditions with Colloidal Sulfur J. Bone and Joint Surg. 1934, p. 119 
is important although he does not recommend its use to the exclusion of all other remedies.

Rawls, Gruskin, and Ressa (1) successfully used a colloidal sulfur solution in the treatment of chronic arthritis. They found that some of the patients reacted to a larger dose than is commonly given although the patients had no reaction to the smaller doses. (2)

Wheeldon and Main/have given the most complete clinical report of the results of colloidal therapy. They used intravenous and intragluteal injections of the preparation "Sulfur-Diasporal" on patients suffering from arthritis who had obtained no relief from any other treatment. The injections of the colloidal sulfur were found to have no reaction when given in clinical doses. The symproms were relieved; the cystine content of the fingernails was increased; the blood odlcium was possibly stabilized; blood sugar was decreased a small amount; the metabolic rate rose some; the sedimentation rate fell; indican in the urine increased indicating increased detoxification; and there was a slight fall in the white blood cell counts, in the hemoglobin, the blood pressure, and in the pulse pressure.

(3)

$\mathrm{Argy} / \mathrm{discovered}$ that in treating arthritis with colloidal sulfur the increase of the cystine in the fingernails depends upon the number of injections of colloidal sulfur.

(1) Rawls, Gruskin, and Ressa, "The Value of Colloidal Sulfur in the Treatment of Chronic Arthritis", Am. J. of the Med. Sci. $\mathrm{v} .190,1935$, pp.400-409

(2) Wheeldon, T. F, and kain, R. M."The Use of Colloidal Sulfur in the Treatment of Arthritis", g. Bone and Joint Surg. 15, 1933, p.94, and $v \cdot 17,1935$, pp. 693-726

(3) Argy, W. F. "Arthritis: Treatment with Sulfur by Intravenous and Intramuscular Injection, J. Bone and Joint Surg. 16, 909-913 
Sullivan and Hess compared the cystine content of fingernails before and after treatment with colloidal sulfur and found that the cystine was increased. Their possible interpretation of the relation of sulfur to arthritis is most interesting. "In the majority of the arthritic cases the low cystine content of the fingernails seems to imply an intoxication factor which draws on the sulfur complexes as, for example, glutathione, and thus diverts the sulfur from its normal channels which would lead to a fingernail containing at least $11 \%$ cystine. The increase of the cystine content in a number of cases of arthritis after injection of sulfur implies that the sulfur directly or indirectly after change by the body combines with the injurious material and thus spares the normal sulfur complexes from being diverted." (1)

Sulfur metabolism in chronic arthritis is disturbed. The cells seem to have lost their ability to retain sulfur just as the cells of the tubercular have lost their ability to retain calcium or the cells or the diabetics to utilize carbohydrates. In rheumatoid arthritis Loeper (2) and his associates have shown that the neutral sulfur of the joint cartilege is one-third below normal and that the total sulfur in the blood is increased. Cawadias(3) has reported that the total sulfur in the urine of arthritics is increased. He believes that this increase is due to improper metabolic processes accompanied by the breakdown of sulfur complexes in the body.

(1) Sullivan and Jess: op. cit. p.187

(2) Rawls, Gruskin and Ressa: op. cit. p. 400-409

(3) Cawadias, A. P."Sulfur Motabolism in Arthritis Deformans", Lancet I, $1927, \mathrm{p} .1283$. 
Race (1) believes the increase of sulfur in the urine of arthritics is due to the deficient oxidation of sulfur in the body.

Thus workers have given almost conclusive evidence that sulfur is a very important factor in the treatment of arthritis. Ihis disease is so much greater an economic waste than even cancer or tuberculosis that an American Committee for the Control of Rheumatism has been formed.

The treatment of arthritis by colloidal sulfur has been so successful that it is causing investigators to study the manner. of action of colloids in the body. Colloidal sulfur is a better remedy than the oral administration of flowers of sulfur and better than many drugs heretofore used in the treatment of arthritis, undoubtedly because it is in the colloidal state. Colloidal particles have a larger surface than do dissolved particles. Colloidal sulfur is more active than plain sulfur which itself is next in activity to oxygen. Woldenberg states: "In the human body all cells are decidedly influenced by colloids. The functions of muscles may be considered as a typical form of colloid reaction, although many of the details are not yet clear. Nowhere else in the technical world can we find available energy changed into such a useful force as when substances are turned into a colloidal state. In the protoplasm of nerve cells the equilibrium is preserved through the enormous surface energy of colloids.

"It is of the highest importance to us to understand that the

(1) Race, J. "Sulfur in Metabolism" Lancet, 2, 1921, p.142 
colloids are the carriers of protoplastic functions, and that the functioning of the cell is influenced throughout by colloidal changes in the surrounding fluid based upon certain fixed laws. The marvelous system of regularity pertaining to the blood current and tissue fluid in the living body strongly guards against any attenpt to influence the functioning of the cell, though clinical experience has taught us that this is possible. The calcium therapy with its solidifying effect uoon the looseness of the colloids during inflammation and the iodine therapy with its loosening effect upon the sclerosed colloids of the ressels through age, gives us decided proof of such influence on the functioning of the cells therapeutically. The entire immunizing therapy is closely allied with the science of colloid chemistry

"It is therefore essential that if any therapeutic method is to be successful it must have an effect upon the colloids of the body." (1)

(1)WoldenberG, S. C. "Sulfur Therapy in the Treatment of Arthritis"? Hed. Rec. 1934, v. 149, p.163. 
II. COLIOIDAL SULFUR 


\section{A. Properties}

Sulfur is insoluble in water, noarly insoluble in alcohol, and slightly soluble in ether and olive oil. Colloidal sulfur is more soluble in water and more active than plain sulfur. The particle of colloidal sulfur ranges in size as do all colloidal particles, from 0.1 to to $1 \mathrm{mu}$, whereas true sulfur solutions have partidles of the magnitude lmu and smaller, and coerse dispersion particles are larger in size than 0.1u. The appearance of the sulfur sol depends upon the size of the particles, the larger the particle size the more turbid, the smaller the particle the more clear. The solutions containing the larger particles will settle out in a very short time. Also the appearance of the sulfur solution depends upon the concentration of the substances used in preparation and the method used. Oden (1) produced solutions of varying particle size by fractionally precipitating the sulfur solutions with sodium chloride of varying concentrations. The resulting solutions varied from turbid and easily settling out sols to a concentrated sulfur sol of bricht yellow color and of very faint turbidity •

Sulfur solutions are similar to those of globulin. Neither is very soluble in water and both require a small amount of electroIyte to cause complete solution. As long as the colloidal sulfur retains its solubility in water it is amorphous and somewhat plastic; it is also negatively charged. Zsigmondy (2) assumed from these

(1) Svedberg, "Colloid Chemistryt" The Chem. Catalog Co. N.Y. 1924, p.64

(2) Zsigmondy and Spear, "The Chemistry of Colloids", John Filey and Sons, N.Y. 1917, p. 131 . 
properties that the amicrons hold tonacjously to the water molecules and to the electrolyte, and that these substances are responsible for the solubility in water. The higher the temperature and the greater the concentration of the hydrochloric acid solution $(0.2 \mathrm{~N}, 0.3 \mathrm{~N}$, and $0.4 \mathrm{~N} \mathrm{HCi})$ the more the solubility of the sulfur increased. Colloidal sulfur is also reversibly precipitated by sodium salts, but irreversibly precipitated by the salts of potassium.

Raffo (1) has shown that well-defined crystals of sulfur come out of colloidal sulfur solutions on long standing. These crystals have a normal melting point and are easily soluble in carbon disulfide but not in water.

Alexander (2) has observed the action of light upon a suspension of sulfur prepared by the action of acid on sodium thiosulfate. By transmitted light the liquid at first appears red; however, according to the concentration of the reagents used in preparation, it soon absorbs less of the short wave lengths and then by transmitted light it appears at first blue and finally violet. Sedimentation follows, amorphous sulfur depositing out. This amorphous sulfur finally crystallizes. The variation in the optical properties of the sulfur suspension has been found to be due to the variation of the size of the sulfur particle in solution. Alexander has also shown that radiations of short wave length increase the speed of the precipitation of sulfur from a suspension.

(1)Zsigmondy and Spear, op. cit. p. 131.

(2)Alexander, J. "Colloid Chemistry" V.1, Chem. Catalog Co. H.Y. $1926, \mathrm{pp} .353-369$. 
Temperature plays an important part in the kinds of colloidal sulfur solutions that will be formed, according to Alexander (I). Temperature increases the solubility of sulfur in an acetone sol or in an alcohol sol.

The size of the sulfur particles will vary with time and light. Alexander (2) has found that the diameter of the sulfur sperules increases with time, ra idly at first, then gradually more slowly. When the grains cease growing, agglutination takes place ond sedimentation eventually results. Dissolved sulfur will eggregate upon the surface of the particles that have separated out. Licht of short wave length will affect this sedimentetion. The former increases particle size more rapidly than the latter. The former increases the velocity of setting of the dissolved sulfur particle on the surface of the grannles, whereas longer wave lengths diminish it. In conclision Alexander states: "The results of the action of light on suspensions of sulfur, which may be attributed to the influence of radiations upon the forces of cohesion, leads to the view that the transformation of soluble into insoluble amor phous sulfur is related to quite analogous phenomena. In this case, on increase in the forces of cohesion of dissolved sulfur brings about the association of dissolved flocks which finally settle out." (\$) (4) Zsigmondy/observed that collodion membranes caused almost all
(1)Alexander, J. op.cit. pp.353-369
(2) Ibid.
(3) Ibid. p.367
(4) Zsigmondy and Spear, op. cit. p. 131. 
of the sulfur to separate from the solution. In the experiments in this research a similar action of collodion membranes on an alkaline polysulfide solution was observed. When the solution touched the membrane, whjte amorphous sulsur precipitated out. However, all the sulfur in the polysulfide solution did not separate out, because when determination of the solution was made it ras. found still to contain quite a bit of the original sulfur. 
B. Methods of Preparation of Colloidal Sulfur

Raffo's method (1) for the preparation of colloidal sulfur was discussed by Zsigmondy and Spear. Raffo prepared a sulfur sol as follows: Fifty grams of orystallized sodium thiosulfate in $30 \mathrm{cc}$. of water are added drop by drop to 70 grams of 1.84 sulfuric acid. The mixture is warmed for ten minutes at $80^{\circ} \mathrm{C}$. and filtered through glass wool. The precipitate is cooled, washed with water, warmed and again filtered. This process is repedted a number of times. The purified sulfur mass is next centrifugalized and finally dissolved in water. The solution is neutralized with sodium carbonate whereby most of the sulfur falls out. The liquid contains about one per cent of sulfur and six per cent of sodium sulfate. The precipitated sulfur dissolves completely in water forming a clear liquid that contains 4.5 per cent sulfur and 1.5 per cont sodium sulfate. By dialysis the salt may be removed partially; however, continued purification will precipitate out the entire sulfur content.

Oden's method (2) uses the same reagents but varies the conditions. Thirty cc. of a three molar solution of sodium thiosulfate are added dropwise to $10 \mathrm{cc}$. of $18 \mathrm{M}$ sulfuric acid which is continuously stirred. The dropping should be at the rate of $2 \mathrm{cc}$. of thiosulfate per minute. The temperature of the reaction mixture should be originally at about $25^{\circ} \mathrm{C}$. and not allowed to exceed

(1)Zsigmondy and Spear, op. cit. p. 129

(2) Thomes, A. W. "Colloid Chemistry", MeGraw Hill Book Co. 1934, p. 118 
$50^{\circ} \mathrm{C}$. Slower addition of the thiosulfate gives a lower yield of colloidal sulfur; and while a higher temperature produces a greater proportion of highly dispersed sulfur, the reaction becomes rather explosive. Temperatures lower than the range given produce a somewhat lower yield and a lower ratio of microscopic particles. Oden recormends that small proportions be made at a time (never over $100 \mathrm{cc.}$ ) and that the reaction vessel be a centrifuge tube. When the addition of the $30 \mathrm{cc}$. of thiosulfate solution has been completed, the mixture is immediately cooled and sufficient sodium chloride is added to precipitate the sulfur. The mixture is centrifuged and the supernatant liquid is removed. Then the residue is treated with water at about $80^{\circ} \mathrm{C}$. which effects redispersion of part of the sulfur. This mixture is centrifuged to throw out the irreversibly coagulated sulfur and the supernatant sulfur hydrosol is then remored by decantation. All the sulfuric acid can be removed by reprecipitation and redissolving but the pentathionic acids cannot be removed in this way. Sols containing as high as 50 per cent sulfur have been made by this process. The equation showing the action may be written as follows: (1)

$$
\begin{aligned}
& 3 \mathrm{Na}_{2} \mathrm{~S}_{2} \mathrm{O}_{3}+3 \mathrm{H}_{2} \mathrm{SO}_{4} \rightarrow 3 \mathrm{H}_{2} \mathrm{~S}_{2} \mathrm{O}_{3}+3 \mathrm{Na}_{2} \mathrm{SO}_{4} \\
& \mathrm{H}_{2} \mathrm{~S}_{2} \mathrm{O}_{3} \rightarrow \mathrm{S}+\mathrm{SO}_{2}+\mathrm{H}_{2} \mathrm{O} \\
& 2 \mathrm{H}_{2} \mathrm{~S}_{2} \mathrm{O}_{3}+2 \mathrm{H}_{2} \mathrm{O} \longrightarrow 2 \mathrm{H}_{2} \mathrm{~S}+2 \mathrm{H}_{2} \mathrm{SO}_{4} \\
& 2 \mathrm{H}_{2} \mathrm{~S}+\mathrm{SO}_{2} \longrightarrow 3 \mathrm{~S}+2 \mathrm{H}_{2} \mathrm{O} .
\end{aligned}
$$$$
3 \mathrm{Na}_{2} \mathrm{~S}_{2} \mathrm{O}_{3}+\mathrm{H}_{2} \mathrm{SO}_{4} \rightarrow 4 \mathrm{~S}+3 \mathrm{Na}_{2} \mathrm{SO}_{4}+2 \mathrm{H}_{2} \mathrm{O}
$$

(1) Svedberg: op. cit. p.67-68 
The amount, of colloidal sulfur decreases when the concentration decreases and more fine grained particles may be obtained at higher concentrations.

Oden's method (1) from sulfur monochloride and water will prepare a colloidal sulfur sol. The procedure is as follows: Seventy cc. of water at $30 \mathrm{C}$. is added to $10 \mathrm{cc}$. of sulfur monochloride and shaken. An exothermic reaction soon takes place accompanied by the evolution of sulfur dioxide. The system is cooled in an ice bath in order to retard the reactions. After 5 to 10 minutes when the erolution of sulfur dioxide ceases, the mixture is treated with a saturated solution of sodium chloride and centrifuged. The precipitated sulfur is peptized on addition of water after decantation of the supernatant liquid. The precipitation and repeptization may be continued until the desired degree of purification is obtained.

Oden, Sobrero and Selmi, Wakenroder, and Debus (2) have all prepared colloidal sulfur from the action of hydrogen sulfide and sulfurous acid. Oden writes the equation as follows:

$$
2 \mathrm{H}_{2} \mathrm{~S}+\mathrm{SO}_{2} \rightarrow 3 \mathrm{~S}+2 \mathrm{H}_{2} \mathrm{O}
$$

Oden (3) has shown that the higher the concentration of the sulfur dioxide the more colloidal sulfur is formed. Also the higher the concentration of the sulfur dioxide and the more pentathionic acids

(1) Thomes, A. W. op, cit. p. 67

(2) Esigmondy and spear; op. cit. p. 129

(3) Svedberg: op. cit. p. 67 
formed in the intermediate steps, the more fine grained particles of sulfur are obtained. At high dilutions when the reaction proceeds according to the simple equation given above, most of the sulfur formed is insoluble. Under these conditions almost no stable colloidal sulfur is formed. The stability seems to depend upon the pentathionic acids present.

Below is a chart showing the effect of the concentration of the sulfur dioxide on the resulting sulfur particles:(l)

\begin{tabular}{cccccc}
$\begin{array}{c}\text { Conc. of } \\
\mathrm{SO}_{2}\end{array}$ & $\begin{array}{c}\text { Colloidal } \\
\text { Sulfur }\end{array}$ & $\begin{array}{c}\text { Insol. non- } \\
\text { colloidal } \mathrm{S}\end{array}$ & $\begin{array}{c}\text { Amicroscopic } \\
\text { particles }\end{array}$ & $\begin{array}{c}\text { nearly } \\
\text { visible } \\
\text { particles }\end{array}$ & $\begin{array}{c}\text { submicro- } \\
\text { scopic } \\
\text { particles }\end{array}$ \\
$1.8 \mathrm{~N}$ & 8.333 & 0.098 & 0.910 & 4.218 & 3.205 \\
$1.44 \mathrm{~N}$ & 9.891 & 0.288 & 0.160 & 2.099 & 7.632 \\
$0.9 \mathrm{~N}$ & 13.022 & 0.402 & 0.052 & 0.216 & 12.764 \\
$0.45 \mathrm{~N}$ & 1.936 & 14.908 & traces & \multicolumn{2}{c}{1.936} \\
$0.225 \mathrm{~N}$ & traces & 16.98 & $-m$ & traces
\end{tabular}

(2)

G. Zanetti/prepared a colloidal form of sulfur by precipitating sulfur from a sulfide solution with an acid, dissolving in a slightly alkaline solution, dialyzing and evaporating. He obtained an amorphous grayish substance containing 95 per cent sulfur. He said that it had good keeping qualities and is soluble is water, giving a milky solution which is stable eren in the presence of sodium arsenite, -iodide, glycerophosphate or gold, calcium or copper salts.

(1) Svedberg: op. cit. p.67

(2) Chemical Abstracts: v. 24, 1930, p. 5861. 
Comrie (1) gives the following directions for the preparation of a 0.1 per cent colloidal sulfur solution to be used in the treatment of rheumatism and arthritis:

Chemicals neoded: $10 \% \mathrm{HCl}, 22 \mathrm{mls} \cdot \mathrm{Na}_{2} \mathrm{~S} \cdot 9 \mathrm{H}_{2} \mathrm{O}, 5 \mathrm{gms} \cdot \mathrm{Na}_{2} \mathrm{SO}_{3} \cdot 7 \mathrm{H}_{2} \mathrm{O}$, $216 \mathrm{gms} . ;$ white of two eggs; sterilized water to one litre. Dissolve the sodium sulfide and sulfite each separately in $250 \mathrm{cc}$. of water, mix together; add the white of egg and thoroughly mix. To this solution add the hydrochloric acid, diluted with $250 \mathrm{cc}$. of water. Mix the solution thoroughly, warm slightly, and add water to one litre. The solution after being carefully dialyzed to remove crystalloids, is then ready for use. Theoretically, the product should contain 1 in 1000 of colloidal sulfur. The chemical action is explained as follows:

$$
\begin{aligned}
& 2 \mathrm{Na}_{2} \mathrm{~S}+4 \mathrm{HCl} \rightarrow 2 \mathrm{H}_{2} \mathrm{~S}+4 \mathrm{NaCl} \\
& \mathrm{Na}_{2} \mathrm{SO}_{3}+2 \mathrm{H}_{2} \mathrm{~S}+2 \mathrm{HCl} \rightarrow 2 \mathrm{NaCl}+3 \mathrm{~S}+3 \mathrm{H}_{2} \mathrm{O}
\end{aligned}
$$

Thus the sodium sulfite is reduced by the hydrogen sulfide produced from the sodium sulfide and hydrochloric acid. The presence of the albumin appears to prevent the aggregation of the sulfur into masses. In use the dose of $1 \mathrm{cc}$. is rendered isotonic by the addition of $0.2 \mathrm{cc}$. of $5.5 \%$ saline solution mixed immediately before injecting.

A. Janek (2) prepared an opalescent sulfur sol which changes into a suspension in 24-36 hours by the reaction of dilute sodium sulfide solution and alcoholic iodine.

(1) Comrie, J. D. op. cit. p. 991

(2) Chomical Abstracts: $\vee \cdot 28,1934, p .394^{2}$ 
Oderberger (1) prepared colloidal solutions of sulfur by intensive mechanical disintegration in the presence of the dispersion medium, a protective colloid, and an electrolyte such as sodium chloride.

Torigian (2) prepared a colloidal sulfur solution suitable for intravenous or intramusoular injection from sodium sulfide, distilled water, dextrin, and sulfur dioxide. The $\mathrm{pH}$ was not less than 7.6 .

(1) Chemical Abstracts: v. 17, 1923, p. 3757

(2) Ibid. $\nabla \cdot 29,1935, \mathrm{p} \cdot 295^{5}$ 
C. Difficulties in Holding Colloidal Sulfur in Solution

Since colloidal sulfur solutions are so easily precipitated by electrolytes, the main difficulty is in regulating the concentration of the electrolyte. As mentioned above, certain authors believe that the solubility of sulfur depends upon the presence of a small amount of electrolyte. Larger amounts, however, will precipitate out the sulfur present. Clean apperatus must be used at all times to eliminate the possibility of introducing electrolytes into the colloidal solution from that source.

The stability of the colloidal sulfur solution also depends upon the size of the sulfur particle. The larger the particle the less stable the solution.

Alkaline polysulfide solutions which were examined fin this research, on standing over a long period of time or upon exposure to air will lose some of their sulfur. Well-defined crystals settle out. These crystals are slightly soluble in water, very soluble in carbon disulfide, chlor of orm and ether. Before exposure to air, however, these solutions were clear. On standing over a period of time the alkaline polysulfide solutions lost some of their alkalinity and the color became slightly lighter. 
III. OBJECTIVES OF THIS RHSEARCH 
An alkaline polysulfide solution prepared in our laboratory showed when taken by mouth to restore the cystine content of the fingernails of arthritic patients much the same as indicated by Sullivan and Hess (1). Likewise this same alkaline sulfide solution used over a period of three years in 680 cases of arthritic patients has given in my instances relief - often much more so than other colloidal preparations. It has been determined that 95 per cent of the patients have been benefited according both to the opinions of physicians in charge and to the statements of the patients. Approximately 2 per cent of the 680 patients were not able to take sulfur orally because of gastro-intestinal sensitivity to sulfur. Five of the 680 of 0.73 per cent showed skin irritation to sulfur in any dilution applied to the back. The average time for improvement to become evident was 5 days. It was, therefore, the problem of this study to investigate the nature of this solution. This examination undertook the general composition of the solution including especially the possible presence of colloidal sulfur and also its dissemination. Determinations were made of the hydrogen-ion concentrations, of the ability of the sulfur in the solution to diffuse through a semi-permeable membrane, and of the effect of the solution on the total sulfur content of the urine of arthritic patients.

(1) Sullivan and Hess: op. cit. pp. 185-188. 
A previous analysis of the alkaline polysulfide solution had been made on February 24, 1936, and it was found to contain:

$$
\begin{array}{ll}
\text { yellow sulfur } & 2.28 \mathrm{gms} . / 100 \mathrm{cc} . \\
\text { milk of sulfur } & 0.10 \mathrm{gms} . / 100 \mathrm{cc} . \\
\text { colloidal sulfur } & 3.85 \mathrm{gms} . / 100 \mathrm{cc} . \\
\text { total solids } & 6.51 \mathrm{gms} . / 100 \mathrm{cc} .
\end{array}
$$

The solutions also contained large amounts of sodium ions, polysulfide ions, some sulfide, sulfate, and a small amount of chloride ions.

The alkaline polysulfide solutions submitted for examinations were clear colored solutions, varying from a deep-red-orange color to a light orange color. The solutions were testeless. They continually gave off hydrogen sulfide. On long standing and on immediate exposure to air, well-defined crystals of sulfur precipitated out. These crystals were slightly soluble in water, very soluble in ether, chlor of orm and carbon disulfide. On neutralization with dilute hydrochloric acid white granular sulfur particles separated out.

The samples made up at various times were allowed to stand in order to note the rate of deterioration if there were such.

The samples were numbered 1-9. Sample 8, made up in January, 1935, was very light orange in color and contained ruch crystalline sulfur in the bottom of the bottle. Sample 9, prepared in April, 1936, was a deeper orange than sample 8, and contained less crystalline sulfur precipitated out than sample 8, but more than samples 1-7. The solutions were very alkaline to litmus and had the odor of hydrogen sulfide. 
IV. PE DETHRMINATIONS OF THE ALKALINE POLYSULFIDE SOLUTIONS 


\section{A. Method}

The Glass Electrode was used in preference to the Quinhydrone Electrode or to the fydrogen Electrode since the quinhydrone reacted with the alkaline polysulfide solution and since the hydrogen electrode was too easily poisoned. The Glass electrode on a Beckman $\mathrm{pH}$ meter consisted of a small calomel electrode and a small quinhydrone electrode both enclosed in elass. The current passing between the two electrodes was directly proportional to the hydrogen ion concentration of the solution. When the electrodes were adjusted to the zero point and the temperature ginge eot, a small amount of the sample was placed in the glass cup and the $\mathrm{pH}$ value read directly. It is a very rapid and very accurate method. This is the only method that can be recommended for the pH determinations of this alkaline polysulfide solution which is unbuffered. 
B. Results

$\begin{array}{cc}\text { Sample number } & \mathrm{pH} \text { value } \\ 1 . & 10.2 \\ 2 . & 10.05 \\ 3 . & 10.25 \\ 4 . & 9.85 \\ 5 . & 10.10 \\ 6 . & 10.025 \\ 7 . & 10.10 \\ 8 . & 7.10 \\ 9 . & 7.20\end{array}$

C. Discussion

On standing over a period of time the $\mathrm{pH}$ values of the solutions were apparently lowered as is shown by the readings on samples 8 and 9. The $p H$ values of semples and 9 varied from 7.1 to 8.0 . Finally, over a period of several reading, checks for samples 8 and 9 were obtained. The readings on samples 1-7 varited only 0.1-0.2. In samples 1-7 the average $\mathrm{pH}$ was 10.082 . The $\mathrm{pH}$ of samples 1-7 were quite uniform, samples 3 and 4 varying the greatest from the average. 
V. THE QUANTITATIVE AIALYSIS OF COLLOIDAL SULFUR 
A. Prevailing Methods

Allport (1) devised a method whereby the sulfur is converted to thiocyanate by the use of potassium cyanide and triethanolamine. This method is suggested as applicable to all pharmaceutical preparations and to sulfur lozenges. It is supposed to be an accurate determination of free sulfur and to be unaffected by the presence of the sulfate group.

Oxidation methods consist of oxidizing a known amount of the sample to the sulfate radical by various oxidizing agents such as liquid bromine, fuming nitric acid, sodium peroxide, aqua regia, and chlorine. For example 0lsen (2) describes a method for determining sulfur by oxidation with fuming nitric acid as follows:

A weighed or known amount of substance is placed in an Erlenmeyer flask. Fuming nitric acid is added from a graduate. $30 \mathrm{cc}$. is sufficient for those quantities of material that will yield not more than one gram of barium sulfate. Allow the mixture to react and cool. Heat over a water bath for about a half an hour. If there are still particles of sulfur flating on the top of the solution, add a little concentrated hydrochloric acid, potassium chlorete, or liquid bromine. Digest over the water bath until the mixture is completely oxidized. Evaporate off the nitric acid. Dissolve the residue in wer and determine the sulfuric acid as barium sulfate.

(1) Chemical Abstracts: $\nabla .28,1934$, p. 727

(2) Olsen, J. C. "Quantitative Chemical Analysis", D. Van Ostrand Co. N. Y. 1915, pp. 102-104. 
An oxidation method for the determination of total sulfur in biological material has been devised by Stockholm and Koch(1). The procedure is given as follows: Into a $100 \mathrm{cc}$. nickel crucible containing $10 \mathrm{cc}$. of 25 per cent sodium hydroxide solution, introduce 0.5 to 2.0 grams of the substance. The covered crucible is then heated on the steam-bath until the mass is almost dry. This requires several hours, but causes considerable decomposition of the complex substances present, so that the sulfur in particular, can later be easily oxidized. In case the evaporation has proceeded too rapidly it is best to add again $10 \mathrm{cc}$. of water and to repeat the slow evaporation. To the slightly moist material $5 \mathrm{cc}$. of 30 per cent $\mathrm{H}_{2} \mathrm{O}_{2}$ are added. very gradually. In some cases it is necessary to stir the mass with a glass rod or to add a few drops of water so as to distribute the reagent properly. During this treatment the heating is continued on the steam-bath.

The material thus partially oxidized is next transferred to a $300 \mathrm{cc}$. Kjeldahl flask, acidified with nitric acid and concentrated over a free flame until salts begin to separate. This concentrated solution is then oxidized while boiling, by the gradual addition of fuming nitric acid and bromine until $10 \mathrm{cc}$. of acid and 40-50 drops of bromine have been used. With material low in, or free from, fat this treatment is usually sufficient to bring about complete oxidation of the organic matter. The solution is next evaporated almost to dryness and after water has again been added

(1) Hawk and Bergeim, "Practical Physiological Chemistry, P. Blakiston's Son and Co. Phil. 1931, p. 459. 
evaporation is repeated to remove most of the nitric acid. When the water solution of this naterial is not absolutely clear, it is filtered and after it has been neutralized with sodium hydroxide and diluted to about $600 \mathrm{cc}$. it is acidified by the addition of $10 \mathrm{cc}$. of concentrated hydrochloric acid. Ten cc. of $0.1 \mathrm{~N}$ sulfuric acid are added, the mixture heated to boiling, and $10 \mathrm{cc}$. of a 10 per cent barium chloride solution added drop by drop. The boiling is continued for 10-15 minutes and then the mixture is heated for 10-12 hours before it is filtered and washed as usual. The filter paper and precipitate are cautiously burned and weighed. Blank estimations are made in exactly the same way. 


\section{B. Method of Determination}

Prevailing methods were not adaptable to the solution under examination; hence the following method was worked out. The method devised is a comination of several of the methods previously described. The principle is based on the oxidation of the smaller particles of free sulfur to the sulfate group, and the oxidation of the sulfide and polysulfide to the sulfate group. The sulfate is procipitated out and determined 2.5 barium sulfate.

The procedure is as follows: Fire cc. of the alkaline polysulfide solution are neutralized with $0.2 \mathrm{~N}$ hydrochloric acid, using litmus as the indicator. White particles of sulfur precipitate. The solution is filtered through No. 500 filter paper (E. H. Sargent and $\left.C_{0}\right)$, the finer particles going through the paper. The slightly turbid solution is o:idized by adding 20-30 $\mathrm{cc}$. of fuming nitric acid and 6-10 cc. of liquid bromine. Allow to stand until the cloudiness disappears and evaporate the solution slowly to remove excess acid and to insure complete oxidation. Dilute and evaporate again to about $30 \mathrm{cc}$. Be sure never to allow the solution to go to complete dryness or the sample will be ruined. Filter if the solution is not clear. Neutralize with sodium hydroxide, dilute to about $600 \mathrm{cc}$. and add $10 \mathrm{cc}$. of concentrated hydrochloric acid. Heat to boiling and add $15 \mathrm{cc}$. of 10 per cent barium chloride. (This amount of barium chloride was found sufficient to precipitate out the sulfates in this solution.) Boil 10-15 minutes. Heat for 8-10 hours to insure complete precipitation. Filter through Ho. 40 Whatman filter paper. ish carefully and weigh the precipitate. 
The sulfur as $S$ may be determined by multiplying the weight of the precipitate of barium sulfate by $0.137(13.7 \%$ of barium sulfate is sulfur).

$$
\text { C. Results }
$$

$\begin{array}{ccc}\text { Sample no. } & \text { sulfur in grams/cc. } & \% \text { sulfur/cc. } \\ 1 . & 0.0112 & 1.12 \\ 2 . & 0.0111 & 1.11 \\ 3 . & 0.0108 & 1.08 \\ 4 . & 0.01076 & 1.076 \\ 5 . & 0.01075 & 1.075 \\ 6 . & 0.0108 & 1.08 \\ 7 . & 0.01025 & 1.025 \\ 8 . & 0.01845 & 1.845 \\ 9 . & 0.01077 & 1.077\end{array}$

Note:

The Loeser Laboratories put into the market ampolletes containing $50 \mathrm{mg}$. of colloidal sulfur in $10 \mathrm{cc}$. and ampules containing $10 \mathrm{mg}$. in $2 \mathrm{cc}$. These samples, having been previously assayed, were run according to our oxidation method and checked with their previous assay. The results obtrined corresponded with those indicated on their standard pharmaceutical preparations. These samples were run merely as a control on our work. 


\section{Discussion}

The average amount of sulfur per cc. of all the samples was 0.01165 grams or 1.165 per cent.

This method we believe determines only the sulfates, polysulfides, and possible colloidal sulfur left in the solution after neutralization with hydrochloric acid. The larger granules of sulfur precipitated by hydrochloric acid remain on the filter paper and the smeller granules pass through the filter. These smaller particles may be colloidal sulfur.

In samples 8 and 9 , although there was a great deal of preoipitated sulfur in the original solution of alkaline polysulfide, there was no less colloidal sulfur than in the other seven solutions. Sample 8 showed more sulfur than all the rest. On neutralization with hydrochloric acid and filtering, only a small portion of the sulfur precipitated in sample 9 , had particles large enough to remain on the filter paper. The particles precipitated out in sample 8 went completely through the paper, as far as we could see. It will be noticed that samples 8 and 9 were less alkaline than the other seven samples; therefore it seems that the less alkaline the solution the smaller the particles of colloidal sulfur precipitated out by dilute hydrochloric acid. 
VI. DIFFUSION OF THE ALKLLINE POLYSULFIDE SOLJTION 
A. Purpose of the Experiments

The purpose of the diffusion experiments was to determine quantitatively the amount of sulfur that will pass through a collodion membrane. In the first set of experiments the amount of sulfur diffusing through the membrane was determined. In the second set of experiments the amount of diffusion was determined after the alkaline polysulfide solution was neutralized with $0.2 N$ hydrochloric acid and filtered.

B. Procedure

Set I: $2.5 \mathrm{cc}$. of the alkaline polysulfide solution was placed in a collodion membrane and allowed to come to an equilibrium with $100 \mathrm{cc}$. of distilled water (samples 1,2, and 3) and with $100 \mathrm{cc}$. of 0.89 per cent saline solution (samples 4, 5, and 9). The solutions were allowed to stand 24 hours or more until equilibrium was established. The solution outside the membrane was treated with liquid bromine and fuming nitric acid to oxidize the sulfur to the sulfate group. Wive.co: of $\mathrm{Br}_{2}$ and $15 \mathrm{cc}$. of acid were usually sufficient. The solution is allowed to stand until the sulfur is completely oxidized. It is then evaporated, diluted and evaporated again to remove excess acid. The solution is neutralized, diluted, acidfied with $10 \mathrm{cc}$. of concentrated hydrochloric acid, heated to boiling, and $15 \mathrm{cc}$. of 10 per cent barium chloride are added. The solution is boiled 10-15 minutes and evaporated for 6-8 hours to insure complete precipitation. The precipitated barium sulfate is 
filtered, ashed and weighed. The sulfur is determined as $\mathrm{S}$.

Set II: $5 \mathrm{cc}$. of the alkaline polysulfide solution are neutralized with $0.2 N$ hydrochloric acid, using litmus as the indicator. The solution is filtered, and the slightly turbid filtrate is caught in a collodion sack. The solution inside the sack is allowed to come to an equilibrium with $200 \mathrm{cc}$. of distilled water (samples 1, 2, and 3) and with $200 \mathrm{cc}$. of 0.89 per cent saline solution (samples 4, 5, and 9). The sulfur diffusing through is determined by the procedure given above, using, however, only $10 \mathrm{cc}$. of the acid and $2 \mathrm{co}$. of liquid bromine in the oxidizing mixture.

Note: The collodion sack was made by pouring comercial collodion in an 8 inch test tube, allowing the collodion to cover completely all the portions of the tube and draining out the tube immediately. 


\section{Results of Diffusion Experiments}

Set I:

$\begin{array}{ccc}\text { No. of sample } & \text { Grams S diffusing through } & \text { Diffusion time } \\ \text { 1. } & 0.053 & 40 \text { hours } \\ \text { 2. } & 0.0678 & 24 \text { hours } \\ \text { 3. } & 0.0629 & 24 \text { hours } \\ \text { 4. } & 0.0674 & 24.5 \text { hours } \\ \text { 5. } & 0.0593 & 26 \text { hours } \\ 9 . & 0.0411 & 41 \text { hours }\end{array}$

Set II:

$\begin{array}{ccc}\text { No. of sample } & \text { Grams } S \text { diffusing through } & \text { Diffusion time } \\ \text { 1. } & 0.06325 & 40 \text { hours } \\ \text { 2. } & 0.0446 & 24 \text { hours } \\ \text { 3. } & 0.0452 & 24 \text { hours } \\ \text { 4. } & 0.0428 & 24 \text { hours } \\ 5 . & 0.04314 & 25.5 \text { hours } \\ 9 . & 0.05606 & 40.5 \text { hours }\end{array}$


D. Discussion

The average amount of sulfur diffusing through the membrane as found in the experiments in Set I, using $2.5 \mathrm{cc}$. of the alkaline polysulfide solution, was 0.05858 grams. In Set II the average amount diffusing through from $5 \mathrm{cc}$ of the alkaline polysulfide solution, neutralized with $0.2 N$ hydrochloric acid, was 0.04917 grams sulfur.

The fact that the sulfur particles are small enough to diffuse through a collodion membrane was established. This could be seen by the eye since the solution outside the sack was cloudy due to small particles of sulfur. The soluble polysulfides and sulfates would naturally go through the membrane since they are in solution and since the alkaline sulfide solution is hypertonic to distilled water and to the normel saline solution used. Although, when the alkaline solution was passed into the collodion sack, a large amount of sulfur adhered to the sides of the sack, an appreciable amount of sulfur diffused through.

The fact that distilled water was used as one medium and normal saline as the other seemed to make no appreciable difference in the amounts of sulfur diffusing through. 
VII. TOTAL SULFUR IN THE URINE OF NORML INDIVIDUALS ATD IN THE URINE OF ARTHRITIC PATIENTS 
A. Purpose of the Experiments

In no instance has any attention been given to the sulfur content of the body intake - only such sulfur as might have been taken in through food. The sulfur excretion in the urine depends upon the sulfur intake. The purpose of the first set of experiments was to determine the total sulfur content of the urine of normal individuals, to note the constancy, if any, of the total sulfur excretion over a period of five days. A second set of experiments was run on the urine of 9 arthritic patients who had been treated with the alkaline polysulfide solution. These arthritic patients were given approximately 5 drops of the alkaline polysulfide solution in each class of water and from 8-10 glasses of the treated water per day. Only 24 hour specimens of urine were examined. The patients had received benefit from this treatment. The purpose of the experiments in set II was to note what, if any, effect an increased amount of sulfur intake would have on the total sulfur in the urine of arthritic patients. 


\section{B. Method}

Benedict's mothod (1) for determining totel sulfur in urine was used. The principle is as follows: the organic matter is the urine is destroyed and all unoxidized sulfur is oxidized to the sulfute form by evaporating and igniting the urine with a solution of copper nitrate and potassium chlorate. The sulfate is precipitated with barium chloride and determined as barium sulfate. The procedure is as follows: Ten cc. of urine are measured into a smell porcelain evaporating dish. $5 \mathrm{cc}$. of Benedict's sulfur reagent are added. (Benedict's sulfur reagent contains 200 gms of copper nitrate, $50 \mathrm{gms}$. of potassium chlorate and distilled water to $1000 \mathrm{cc}$ ) The contents of the dish are evaporated slowly over a free flame which is regulated to aroid loss by splattering. When dryness is reached the flame is raised slightly until the entire residue has blackened. The flame is then turned up in two stages to the full heat of the bunsen burner and the contents of the dish are heated to redness for ten minutes, after the black residue (which first fuses) has become dry. This heating is to decompose the last traces of the nitrate and chlorate. The flame is removed and the dish allowed to cool. Ten to $20 \mathrm{cc}$. of dilute $(1: 4)$ hydrochloric acid are added to the residue, which is warmed gently until the contents have completely dissolved. A clear sparkling solution is obtained. With the aid of a stirring rod the solution is washed into a smali Erlenmeyer flask, diluted with cold distilled water to $100-150 \mathrm{cc} ., 10 \mathrm{cc}$. of a 10 per cent barium chloride solution added drop by drop, and

(1) Hawk and Bergeim: op. cit. p. 872 . 
the solution allowed to stand for about an hour. It is then shaken up and filtered through quantitative ashless filter paper, ashed, and weighed. The quantity of sulfur as $\mathrm{SO}_{3}$ may be determined as follows :

Mol. wt. $\mathrm{BaSO}_{4}:$ wt. of $\mathrm{BaSO}_{4}:: \mathrm{Mol}$. wt. $\mathrm{SO}_{3}: \mathrm{x}$ (wt. of $\mathrm{SO}_{3}$ in grams) 233.43:y:: $80.06: x$ (wt. of $\mathrm{SO}_{3}$ in grams in the quantity of urine used). 
C. Results of the Determinations on Normal Urines

Set I a.

April 16.

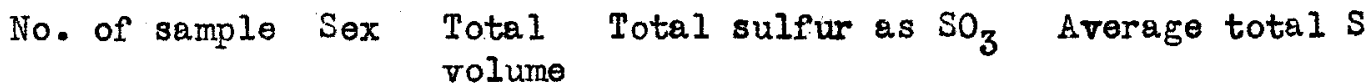

$\begin{array}{lllll}\text { 1. } & \text { F. } & 983 \mathrm{cc} \cdot 1.523 & 1.6514 & 1.5872 \\ \text { 2. } & \text { F. } & 920 \mathrm{cc} \cdot 1.5135 & 1.5308 & 1.5311 \\ \text { 3. } & \text { F. } 910 \mathrm{cc} \cdot 1.2166 & 1.1709 & 1.1937 \\ \text { 4.. } & \text { M. } 1300 \mathrm{cc} .2 .028 & 2.1047 & 2.0663 \\ \text { 5. } & \text { H. } 1680 \mathrm{cc} .2 .846 & 2.8627 & 2.8543 \\ \text { 6.. } & \text { M. } & 1966 \mathrm{cc} .2 .236 & 2.233 & 2.2345\end{array}$

Set I b.

April 21.

\begin{tabular}{|c|c|c|c|c|c|c|}
\hline $\begin{array}{l}\text { No. of } \\
\text { sample }\end{array}$ & Sex & $\begin{array}{l}\text { Total } \\
\text { volume }\end{array}$ & Total N & $\begin{array}{l}\text { Total su } \\
\text { as } \mathrm{SO}_{3}\end{array}$ & ulfur & Average total S \\
\hline 1. & F. & $1380 \mathrm{cc}$ & 14.48 & 1.918 & 1.92 & 1.919 \\
\hline 2 & $F$. & $980 \mathrm{cc}$ & 17.84 & 2.003 & 1.965 & 1.984 \\
\hline 3. & F. & $920 \mathrm{cc}$ & 17.90 & 1.1076 & 1.1076 & 1.1076 \\
\hline 4. & M. & $1720 \mathrm{cc}$ & 17.09 & $2 \cdot 3426$ & 2.3564 & 2.3495 \\
\hline $5 \cdot$ & M. & $1230 \mathrm{cc}$ & 12.096 & 3.576 & 3.585 & 3.5805 \\
\hline 6. & M. & $1090 \mathrm{cc}$ & 14.83 & 3.550 & 3.519 & 3.5345 \\
\hline
\end{tabular}




\section{Discussion}

Hawk and Bergeim (1) state that the average total sulfur as $\mathrm{SO}_{3}$ excretion per day is 2.5 grams. However, this amount depends upon the decomposition of exogenous and endogenous protein. A definite atio betweem the total $N$ and the total $S$ is expeoted. The ratio $5: 1$ has been suggested, but this has not been proven conclusively yet. In Set I a the results showed the total sulfur slightly lower than the average, 2.5 grams, except sample 5 . In Set I b samples 1,2 and 3 were all below the average. Sample 4 was nearer average than any other sample. Samples 5 and 6 in Set $I$ b were 1 gram above the average. It will be noticed that the total sulfur excretion for males was higher than for females. It will be also noticed that over a period of 5 days the total sulfur excretions were not very constant, except in the cases of samples 3 and 4. The ratio of $5: 1$ for $N: S$ was not observed in the 6 samples in set I b. 
E. Results of the Determinations on the Urine of Arthritic Patients Set II.

\begin{tabular}{|c|c|c|c|c|c|}
\hline Patient & Sex & Age & $\begin{array}{l}\text { Condition of } \\
\text { urine }\end{array}$ & Total volume & Indican \\
\hline 1. & $\mathrm{M}$ & 70 & $\begin{array}{l}\text { turbid, coral } \\
\text { color, heavy } \\
\text { sediment }\end{array}$ & $500 \mathrm{cc}$ & pos. \\
\hline 2. & F. & 65 & normal & $1200 \mathrm{cc}$ & neg. \\
\hline 3. & F. & 70 & normal & $1350 \mathrm{cc}$ & neg. \\
\hline 4. & F. & 42 & normel & $1250 \mathrm{cc}$ & neg. \\
\hline 5. & $\mathrm{~F}$ & 45 & normal & $1300 \mathrm{co}$ & neg. \\
\hline 6. & $\mathrm{~F}$. & 75 & normel & $1500 \mathrm{cc}$ & neg. \\
\hline 7. & $\mathrm{~F}$ & 51 & normel & $2500 \mathrm{cc}$ & neg. \\
\hline 8. & M. & 36 & norma 1 & $750 \mathrm{cc}$ & neg. \\
\hline 9. & $\mathrm{~F}$. & 75 & normal & $1250 \mathrm{cc}$ & neg. \\
\hline
\end{tabular}

$\begin{array}{cccccc}\text { Patient } & \text { Total N } & \text { Total P } & \text { Total S } & \text { Average total S } \\ \text { 1. } & 13.98 & 2.075 & 2.731 & 2.661 & 2.696 \\ \text { 2. } & 8.03 & 1.68 & 1.189 & 1.197 & 1.193 \\ \text { 3. } & 5.13 & 1.46 & 1.343 & 1.402 & 1.3725 \\ 4 . & 14.53 & 2.5 & 2.971 & 2.977 & 2.974 \\ 5 . & 6.877 & 1.404 & 1.556 & 1.543 & 1.5495 \\ 6 . & 6.60 & 1.65 & 1.573 & 1.569 & 1.571 \\ 7 . & 10.8425 & 2.025 & 2.135 & 2.135 & 2.135 \\ 8 . & 9.90 & 2.94 & 2.775 & 2.708 & 2.2415 \\ 9 . & 9.15 & 1.82 & 1.779 & 1.779 & 1.779\end{array}$




\section{F. Discussion}

Total nitrogen by the Kjeldhal method (1), total phosphorous by the Uranium Acetate method (2), as well as the total sulfur were run on these samples to note what, if any, significant relationship between the excretion of nitrogen, sulfur and phosphorous. The normal total nitrogen excretion per day varies usually from 12-18 grams. Samples 1 and 4 were the only ones within the normal range. The others were much lower than normal.

The average amount of phosphorous as $\mathrm{P}_{2} \mathrm{O}_{5}$ excreted per day is 2.5 grams. Samples 1, 4, 7 and 8 varied between 2.0 and 3.0 grams. The other samples were lower but none was below 1.4 grams.

The total sulfur excretion in these cases never went above 2.9 grams, the average normal sulfur excretion being 2.5 grams. The amount of sulfur in the arthritic urines corresponded quite closely with the amount excreted in the normel urines reported in Sets I a and I b.

(1) Hawk and Bergeim: op. cit. p. 814

(2) Ibid. p. 876 
G. Comparison and Causes of Possible Discrepancies

Cawadias (1) has reported that in the urine of arthritic patients the totel sulfur excretion increases, due to improper metabolic processes, accompanied by the breaking down of sulfur complexes in the body and their consequential elimination in the urine. These experiments were run not as a duplicate of Cawadias" experiments nor to disprove any of his findings. Instead of finding an increased amount of total sulfur in arthritic urines, we found an average amount or below averare amount present. It is believed that in these cases the sulfur depletion had already occurred before the patients applied for treatment, and that when this sulfur depletion is taking place, then the increased amount of sulfur in the urine will be found. Therefore, upon treatment with the alkaline polysulfide solution, the sulfur from the polysulfide should be utilized in helping to restore the sulfur compounds in the tissues that have been depleted; and thus no additional amount of sulfur in the urine should be expected.

(1) Cawadias: op. cit. p. 1283 
VIII. SUMHARY OF CONCLUSIONS 
From studies of the chemical conduct of this alkaline polysulfide solution and from studies of its behavior as a therapoutic agent in arthritis, the conclusions drawn would indicate three possible explanations of its action:

1. Either colloidal sulfur is present to begin with; or 2. the polysulfide, when it is absorbed through the intestinal luma as the polysulfide, allows minute colloidal sulfur particles to split off from the $\mathrm{Na}_{2} \mathrm{~S} x$ in the blood stream; these colloidal sulfur particles can then be utilized; or

3. the polysulfide itself when it reaches the deficient areas allows the additional sulfur ( $x$ sulfur in the formula) to participate in the resynthesis of the sulfur compounds that are deficient. The alkaline sulfide solution has the characteristics of other colloidal preparations used by methods indicated in the body of this thesis. Its apparent therapeutic value is that it is much more rapid in action than the colloidal preparetions only. The effectireness may be due to more diffusible colloidal sulfur held in the solution to begin with or to the fact that a more diffusible or more easily utilized form of sulfur forms after absorption of the alkaline polysulfide solution itself. 
BIBLIOGRA PHY 
Bibliography

Texts :

Aloxander, J. Colloid Chomistry, V. 1, Chemical CataloE Co. N. Y. 1926

Getman, F. H. and Daniels, F. Outlines of Theoreticel Chemistry,

John Wiloy and Sons, N. Y. 1927

Hawk, P. B. and Bergoim, O. Pratical Physiological Chemistry, P. Blakiston's Son and Co. Philadelphia, 10th edition.

Olson, J. C. Quantitative Chemical Analysis, D. Van Ostrand Co. N. Y. 1915

Peters, J. C. and Van Slyke, D. D. Quantitative Clinical Chemistry, Williams and Wilkins Co. 1932, v. 1

Svedberg, Colloid Chemistry, The Chemical Catalog Co. N. Y. 1924

Thomas, A. W. Collojd Chemistry, HeGraw-Hill Book Co. 1934

Zsigmondy, R. and Spear, E. B. The Chemistry of Colloids, John Villey and Sons, 1917, N. Y.

Journals :

Argy, W. F. Arthritis: Treatment with Sulfur by Intravenous and Intramuscular Injection, Journal of Bone and Joint Surgery, v. 16, Det. 1934, pp. 909-913.

Cawadias, A. P. Sulfur. Hetabolism in Arthritis Deformans, Lancet I, $1927, \mathrm{p} \cdot 1283$

Chemical Abstracts: $v \cdot 17,1923, p \cdot 3757$; $.24,1930, p \cdot 5861$; จ. 28, 1934, p. $394^{2} ;$ v. 28, 1934, p. $727^{l} ;$ v. 29,1935, p. $295^{5}$.

Comrie, J. D. The Treatment of 'Trench Rheumatism' and HIlied Conditions with Colloidal Sulfur, Lancet, I, 1917, p. 991 
Dyer, H. M. and Du Vigneaud, V. J. Utilization of Glutathione in Connection with a Cystine-deficient Diet, Journal of Biological Chemistry, v. 115, Sept. 1936, pp. 543-549.

Exelby, P. A. Results of Treating Cases of Type II Arthritis in the Standford Clinic, Journal of Laboratory and Clinical Medicine, v. 15, 1930, pp. 1285-1.290.

Harris, N. G. Treatment of General Paralysis of the Insane by Injection of Sulfur, Lancet, 1930, pp. 1068-1069.

Gutman J. Use of Modern Drugs in the Treatment of Disease, Medical Rec ord, 1935, p. 567 .

Hopkins, F. G. and Dicon, M. Glutathione: A Thermostable Oxidation and Reduction System, Journal of Biological Chemistry, v. 54, $1922, \mathrm{p} .527$.

McCartan, W. and Beef, D. P. H. Treatment of Dementia Praecox with Sulfosin, Lancet, 1932 , i. p. 340

Mokay R. P. Sulfur in the Production of Fever, Archives of Neurology and Psychiatry, v. 26, 1931, p. 102 .

Morgulis, S. Sulfur Metabolism and Partition of Sulfur in the Urine of Fasting Dogs, Journal of Biological Chemistry, 1928, pp . 627-645. Osterberg, A. E. and Rubenstein, M. W. and Goecherman, W. H. Absorption of Sulfur Compounds During Treatment by Sulfur Baths, Archives of Dermatology and Syphilology, v. 20, 1929, pp. 158-166. Parmenter, D. C. Sulfur Therapy in Arthritis, Kentucky Medical Journal, v. 35, Jan. 1937, p.14

Power, T. D. Leucopoietic Value of Sulfur, Lancet i, 1932, p. 338. 
Race, J. Sulfur in Metabolism, Lancet, 2, 1927, p. 142

Rawls, Gruskin, and Ressa: The Value of Colloidal Sulfur in the

Treatment of Chronic Arthritis, American Journal of the Medical Sciences, $\nabla \cdot 190,1935, \mathrm{pp} .400-409$.

Schroeder, K. Sulfos in Treatment of General Paralys is and Other Disorders, Lancet, II, 1929, pp. 1081-1084.

Senturia, B. D. Results of Treatment of Chronic Arthritis and

Rheumatoid Conditions with Colloidal Sulfur, Journal of Bone and Joint Surgery, 1934, p. 119.

Shilvock, W. H. and Berm, M. B. Pyrogenic Action of Sulfur in Olive Oil, Lancet 2, 1930, p. 347 .

Soshen D. and Spanbock, J. Intrarenous Injections of Colloidal

Sulfur in the Treatment of Rheumatoid and Ostooarthritis, Medical Record, v. 142, 1935, pp. 332-334.

Sullivan, H. X. and Hess, W. C. Cystine Content of Fingernails in Arthritis, Journal of Bone and Joint Surgery, Jan. 1934, pp. 185-188. Tunnicliffe, H. E. Glutathione: Relation Between the rissues and the Oxidized Dipeptide, Biochemical Journal, v. 19, 1925, p. 119.

Waller, L. M. and Allen, E. V. The Use of Sulfur for the Production of Fever in Peripheral Vascular Diseases, Annals of Internal Medicine, v. 5, 1931-32, p. 478 .

Theeldon and Wain: The Use of Colloidal Sulfur in the Treatment of Arthritis, Journal of Bone and Joint Surgery, v. 15, 1933, p. 94; จ. 17, 1935, pp. 693-726.

Woldenberg, S. C. Sulfur (Colloidal) Therapy in the Troetment of Arthritis, Medical Bulletin of the U.S. Veterans Administration, v. 12, 1935-36, p. 10-26. 
Toldenberg, S. C. Sulfur Therapy in the Treatment of Erthritis, Medical Record, v. 149, 1934, p. 161. Woldenberg, S. C. The Treatment of Arthritis with Colloidal Sulfur, Southern Medical Journal, v. 28, 1935, pp. 875-881. 